\title{
Microbiota Profile with Stunting Children in West Sumatera Province, Indonesia
}

\author{
Masrul Masrul $^{1 \star}$, Doddy Izwardy ${ }^{2}$, Ikhwan Resmala Sudji $^{3}$, Idral Purnakarya $^{4}$, Syahrial Syahrial $^{4}$, Ricvan Dana Nindrea ${ }^{5}$ \\ ${ }^{1}$ Department of Nutrition, Faculty of Medicine, Universitas Andalas, Padang, Indonesia; ${ }^{2}$ Director of Community Nutrition, \\ Ministry of Health, Republic of Indonesia; ${ }^{3}$ Biomedical Laboratory, Faculty of Medicine, Universitas Andalas, Padang, Indonesia; \\ ${ }^{4}$ Faculty of Public Health, Universitas Andalas, Padang, Indonesia; ${ }^{5}$ Department of Public Health and Community Medicine, \\ Faculty of Medicine, Universitas Andalas, Padang, Indonesia
}

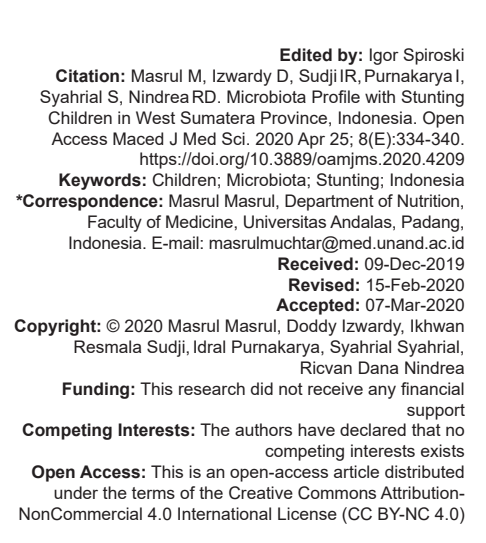

Introduction

Stunting is the underlying cause of almost half of all deaths in five children. Stunting is a result of the systemic conditions of chronic malnutrition. A child can develop stunting in the first 2 years of life and mostly cause by nutritional deficiencies and infectious diseases [1]. In 2014, there were 159 million children under five five years in the world live in low-income countries [1], [2]. Data from the Ministry of Health, Republic of Indonesian reported that there were 7.6 million (37\%) stunted children. The percentage of stunted children in West Sumatra Province is above the national rate of $46.1 \%$ [3]. That number indicates that many children need mvore attention because they do not grow well.

The World Health Organization's Global Target for Reducing Childhood Stunting by $40 \%$ in 2025 [4]. The reduction of stunting children included in the United Nations Sustainable Development Goal \# 2 [5]. The Government of Indonesia has established policies to prevent and reduce the number of stunting, but it is still not running optimally. The modeling of nutrition programs from 34 countries shows that the implementation of nutritional interventions needed comprises folic acid supplementation, balanced dietary protein for mothers, calcium supplementation for mothers, multiple micronutrient supplementation during pregnancy, breastfeeding promotion, Vitamin A, and zinc supplementation with a total coverage $90 \%$, but it is only $15 \%$ play a role in reducing the occurrence of stunting [6].

The failure of these interventions indicates that additional interventions are needed to improve the growth of stunted children. The main obstacle to this intervention and prevention of stunting is the lack of understanding about mechanisms underlying stunted child growth. In addition, until now, there is no biological marker of growth that can be used to monitor children's development other than physical examination (anthropometry). This biomarker is needed to differentiate the population of children who might benefit from any given intervention and to monitor the response from the intervention [7].

The previous studies found from dietary nutrients, the human gut microbiota have been found to be associated with malnutrition [7], [8], [9]. Few studies based on comparative metagenomic analysis addressed the questions related to variations in taxonomic composition of gut microbiota between health and malnutrition [8], [9]. Based on this illustrated, 


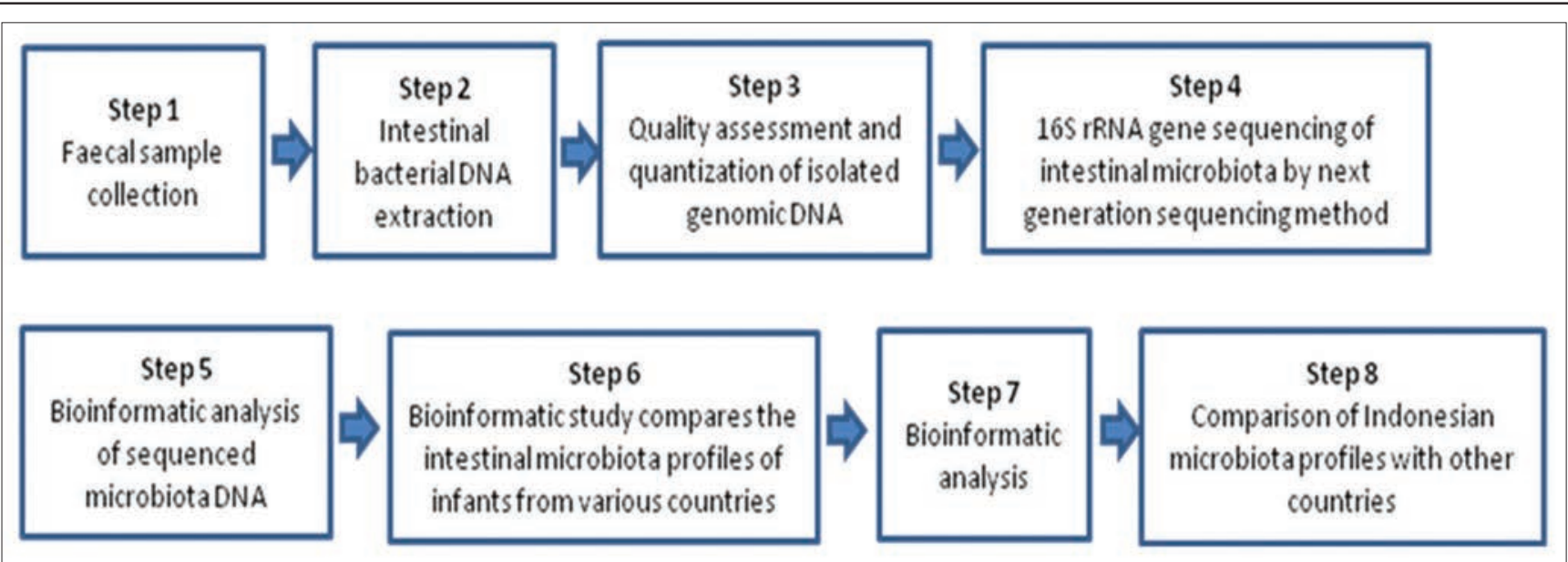

Figure 1: Research procedure

we design the concept of stunting prevention based on the condition of the child's metabolic system and various factors that inhibit the work of the metabolic system, specifically, inhibition of growth hormone, environmental enteric dysfunction (EED), intestinal microbiota dysfunction, and systemic inflammation [7], [8].

\section{Materials and Methods}

\section{Study design and sample}

In this case-control study, we collected 96 samples with 48 stunting children and 48 non-stunting children in Pasaman and West Pasaman district as stunting locus areas in West Sumatra Province, Indonesia. All study subjects met the inclusion criteria: Children $\leq 3$ years of age and they did not suffer from gastrointestinal disorders.

\section{Study procedure}

The procedure of this study consisted of eight steps [Figure 1]. This study passed the ethical review by the Ethics Committee of the Faculty of Medicine, Universitas Andalas, Padang, Indonesia (No. 359/ KEP/ FK/ 2019).

\section{Data collection technique}

Stool samples collected aseptically in sterile fecal containers and transported to the laboratory in dry ice within a maximum of $6-8 \mathrm{~h}$ after collection. Stools collected using pampers or stool containers. Total bacterial DNA was extracted from $200 \mathrm{mg}$ of stool samples using the QIAamp DNA Stool Mini Kit (Qiagen, USA). To ensure maximum lysis of bacterial cells, samples were mechanically lysed using $0.1 \mathrm{~mm}$ zirconium beads and mini-bead beaters (BioSpec Products, Inc., USA). The steps for extracting stool samples are shown in Figure 2.

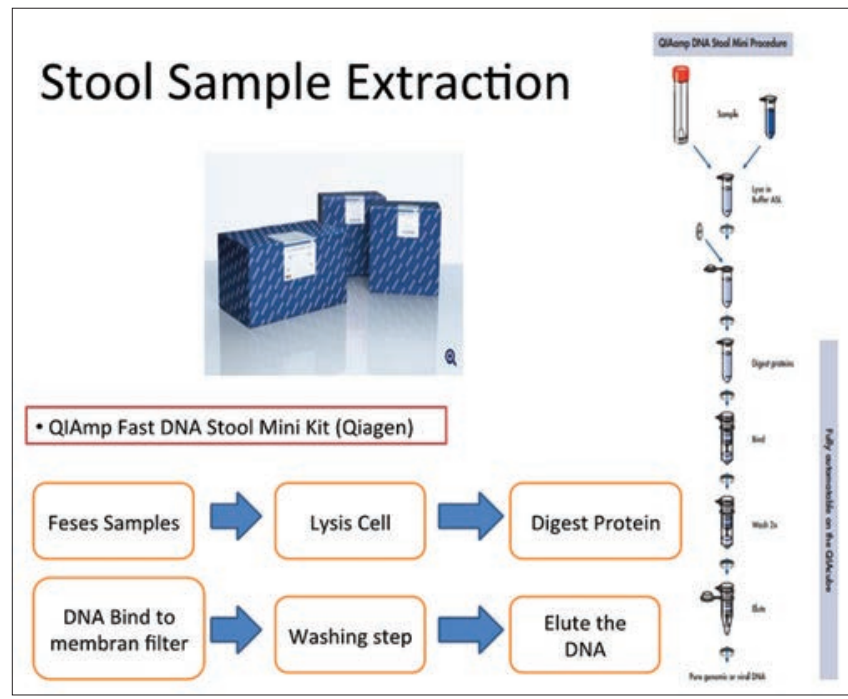

Figure 2: Isolation and extraction of DNA from fecal samples

\section{Data analysis}

Quality assessment and quantization of isolated genomic DNA

The quality and concentration DNA of each sample was assessed using a NanoDrop ND-1000 spectrophotometer (Thermo Scientific, USA) and then visualized using $0.8 \%$ agarose gel electrophoresis. Samples with an OD260/ OD280 >1.8 ratios, OD260/OD230 ratio $>1.9$, DNA concentrations between 250 and $500 \mathrm{ng} / \mu \mathrm{L}$, and without evidence of RNA contamination or DNA degradation were used to prepare the DNA library for overall genome sequencing. The isolated DNA was visualized with an electrophoretic gel to see its quality (Figure 3 ).

Figure 3 shows the quality of isolated DNA which is a good result.

Analysis of the Intestinal microbiota using 16S rRNA gene sequencing. The DNA library was prepared by following the protocol of the Illumina 16S Metagenomic Sequencing DNA Library (Part \# 15044223 Rev. B, Illumina, CA, USA). 


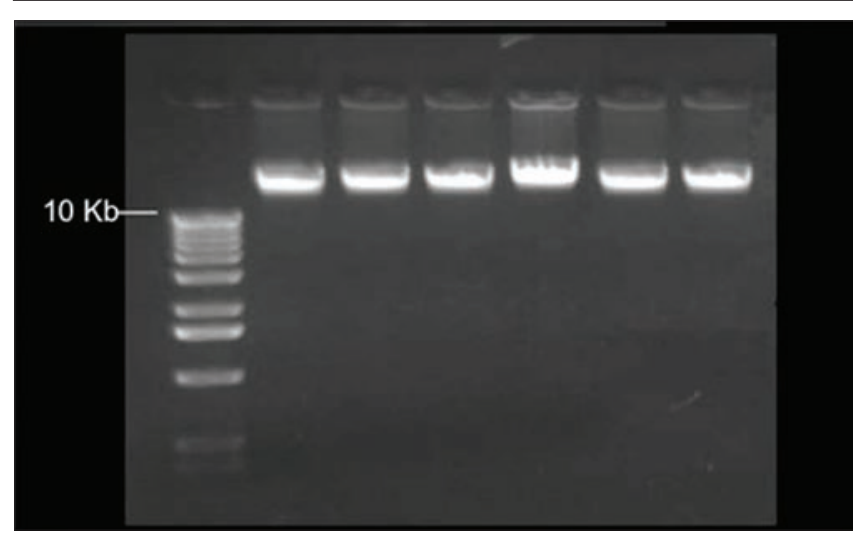

Figure 3: DNA isolated from fecal samples

The hypervariable region V3-V4 of the $16 \mathrm{~S}$ rRNA gene was amplified using the universal primer Illumina: Primary forward locus special SD-Bact0341-bS-17, 5'-CCTACGGNNGGCWGCAG-3 carrying, carrying forward primer overhang adapter,5'-TCGTCGGCAGCGTCAGATGTGTATAAGAGA CAG-3, and primary reverse SD-Bact-0785-aA-21, 5'-GACTACHVGGTATCTAATCC-3 ', which connects the overhang adapter sequence, $5^{\prime}$-GTCTCGTG GACAGGAGAGAGAGAGAGAGAGAGAGAGA GAG-3 AG and reverse primer SD-Bact-0785-aA-21, 5'-GACTACHVGGTATCTAATCC-3 which connect reverse overhang adapter5'-GTCTCGTGGACAGGAG GAGTAGGAGTAGGAGTAGGAGAGAGAGAGAGGAK.

During the amplicon PCR step, if genomic DNA concentration is more than $3 \mathrm{ng} \mu \mathrm{L}-1$, it would be normalized first to $3 \mathrm{ng} \mu \mathrm{L}-1$, and $5 \mu \mathrm{L}$ of normalized DNA used in the PCR reaction; if not, $5 \mu \mathrm{L}$ of genomic DNA is used for the PCR reaction regardless of DNA concentration. Using primers with a concentration of 5 $\mu \mathrm{M}$, the reaction was carried out in a final volume of $25 \mu \mathrm{L}$. The DNA library for each sample normalized and collected into one DNA library in the same molar number. DNA sequences from the DNA library were read using the Illumina MiSeq platform using the $2 \times$ 300-bp v3 MiSeq Reagent Kit (Illumina, CA, USA).

The scheme for library making is shown in Figure 4

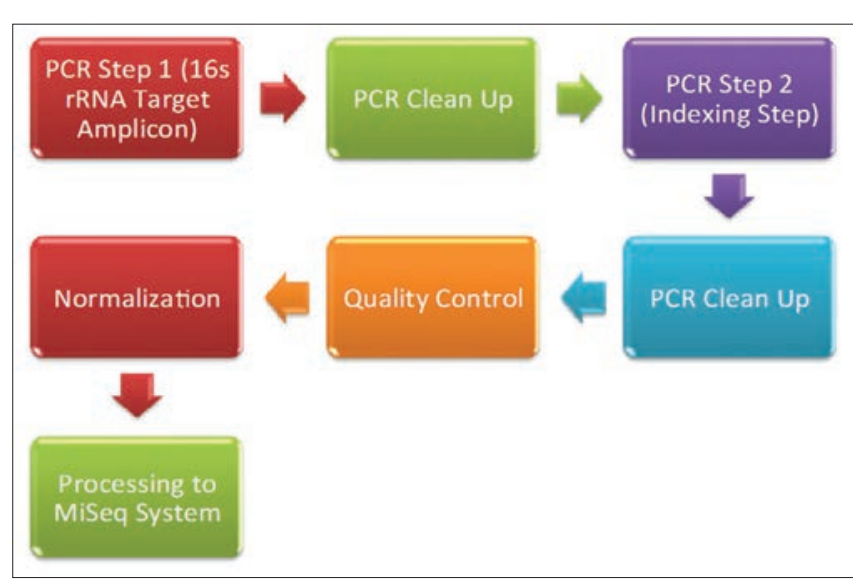

Figure 4: The process of making intestinal microbiota DNA library
Bioinformatic analysis of sequenced microbiota DNA sequences

Data of low-quality sequencing results will be removed using the PyroNoise algorithm in Mothur17 based on the following criteria: (a) Raw readings shorter than $400 \mathrm{bp}$; (b) a sequence that produces more than 8 homopolymers; (c) more than 2 mismatches in the primary, or (d) one or more mismatches in the barcode. Microbiome analysis implemented using the Quantitative Insights Into Microbial Ecology (QIIME) platform. In brief, the 16S rRNA (OTU) operational taxonomy unit grouped using a reference OTU retrieval protocol that was available based on a $97 \%$ nucleotide similarity with the UCLUST algorithm. The ChimeraSlayer software was used to delete chimeric sequences. The most abundant sequence of each OTU was chosen to determine the phylogeny of the OTU based on the taxonomic classifier, RDP classifier. Profiles of taxonomic relative abundance at taxa level (phylum, class, order, family, and genus) were generated based on OTU annotations. The diversity between samples (beta diversity) was evaluated by weighted and unweighted UniFrac distances and calculated by QIIME pipes.

\section{The bioinformatics study compares the intestinal microbiota profiles of infants from various countries}

To compare the composition of intestinal microbiota among infants from many cities in Indonesia, various articles discussing this were collected using the following inclusion criteria: (1) Original study papers reporting independent data; (2) using 16S rDNA sequencing; (3) performed on healthy infants aged 1-24 months; (4) sample size not $<10$ samples; and (5) original data can be downloaded. The microbiota taxonomic profile was analyzed based on OTU annotations for each country separately. Principal component analysis (PCA) is then carried out based on profiles obtained from various cities in Indonesia.

\section{Results}

Table 1 shows that the age of respondents in healthy children was $2.45(0.78)$ and stunted children was 2.51 (0.91), WAZ score was -1.62 (1.05), HAZ was -2.18 (1.22), and WHZ was -0.51 (1.17). Stunting children have more family members than healthy children. The average income of families with stunted children is lower than healthy children. Healthy children are known to have a better role in parenting and father's support than stunting children. All respondents in healthy children have been immunized and get Vitamin $A$, it was different in stunting children where no immunization found and few children got Vitamin $A$. 
Table 1: Characteristics of respondents

\begin{tabular}{ll}
\hline Characteristics & Details \\
\hline Age (years), mean (SD) & \\
Healthy children & $2.45(0.78)$ \\
Stunted children & $2.51(0.91)$ \\
WAZ, mean (SD) & $-1.62(1.05)$ \\
HAZ, mean (SD) & $-2.18(1.22)$ \\
WHZ, mean (SD) & $-0.51(1.17)$ \\
Number of family members, mean (SD) & \\
$\quad$ Healthy children & $4.4(4.00)$ \\
Stunted children & $4.8(1.73)$ \\
Family income (IDR), mean (SD) & $635,406(378,686)$ \\
$\quad$ Healthy children & $355,768(362,950)$ \\
$\quad$ Stunted children & \\
Mother as a caregiver, (f/\%) & $44(91.4)$ \\
$\quad$ Healthy children & $54(88.3)$ \\
$\quad$ Stunted children & \\
Husband involvement, (f/\%) & $7(11.4)$ \\
$\quad$ Healthy children & $5(9.6)$ \\
$\quad$ Stunted children & \\
Complete immunization, (f/\%) & $48(100.0)$ \\
$\quad$ Healthy children & 0 \\
Stunted children & \\
Administration of Vitamin A, (f/\%) & $47(97.1)$ \\
$\quad$ Healthy children & $1(1.63)$ \\
Stunted children &
\end{tabular}

The results of the bioinformatics analysis based on the number of species based on the genus are shown in Table 2.

Table 2: Number of species based on genus among respondents

\begin{tabular}{lll}
\hline Genus & Species & Percentage \\
\hline Firmicutes & 153 & 47.52 \\
Proteobacteria & 68 & 21.12 \\
Bacteroidetes & 52 & 16.15 \\
Actinobacteria & 22 & 6.83 \\
Fusobacteria & 6 & 1.86 \\
Tenericutes & 4 & 1.24 \\
Lentisphaerae & 3 & 0.93 \\
Synergistetes & 3 & 0.93 \\
TM7 & 3 & 0.93 \\
Cyanobacteria & 2 & 0.62 \\
Spirochaetes & 2 & 0.62 \\
Verrucomicrobia & 2 & 0.62 \\
Euryarchaeota & 1 & 0.31 \\
Elusimicrobia & 1 & 0.31 \\
Total & 322 & 100 \\
\hline
\end{tabular}

Table 2 shows that the total number of bacterial species that were identified in the respondent's intestine was 322 species. The dominant bacteria in intestinal microbiota profile of Pasaman and West Pasaman district, West Sumatera Province, Indonesia, among stunting children were Firmicutes (47.52\%), Proteobacteria (21.12\%), and Bacteroidetes (16.15\%).

Figure 5 shows that the highest proportions of species based on the genus were Firmicutes, Proteobacteria, and Bacteroidetes.

Figure 6 shows in intestinal of stunting children identified 61 species of bacteria which were only found in the intestinal of stunting children and not found in non-stunting children.

Comparison of types of the intestinal microbiota of stunting and normal children in Yogyakarta, Bali, and Pasaman, West Pasaman district (West Sumatera Province), Indonesia, is shown in Figure 7.

The intestinal microbiota profile of Pasaman and West Pasaman district, West Sumatera Province, Indonesia, showed the difference with children from

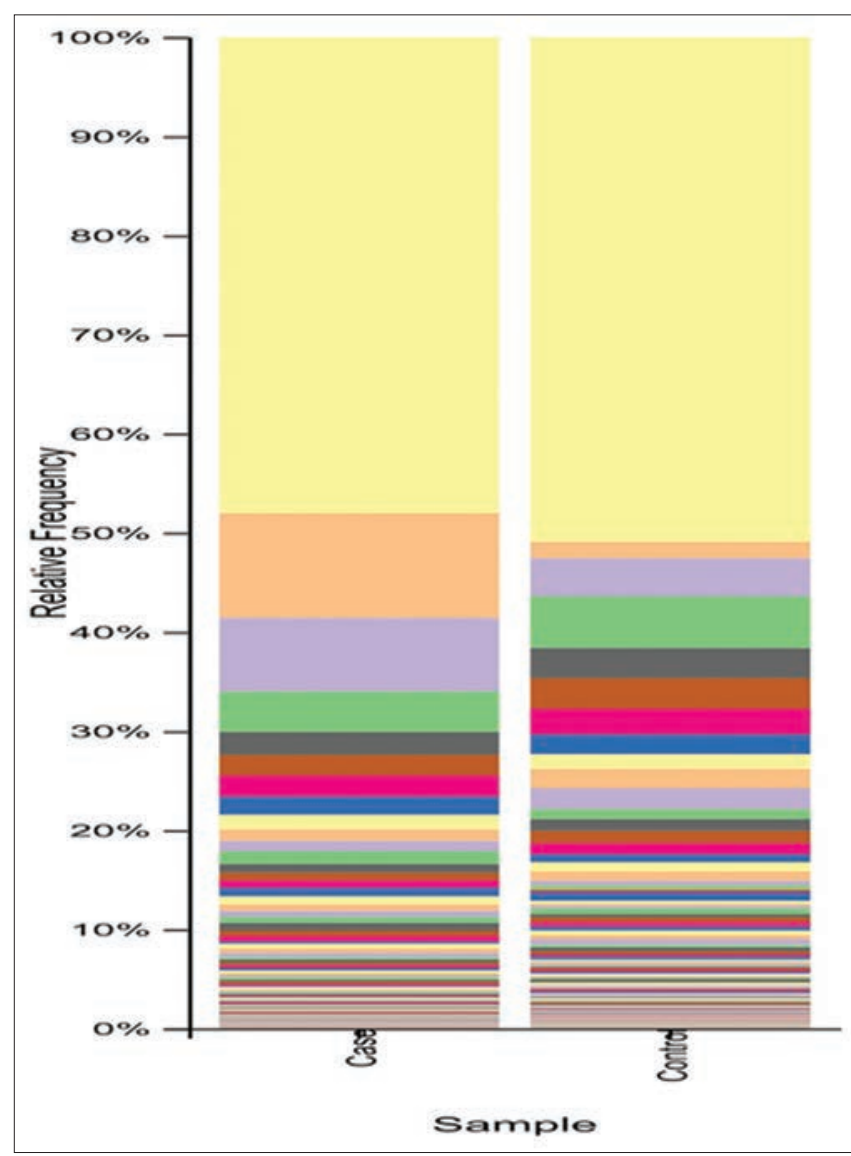

Figure 5: The intestinal microbiota profile of stunting and non-stunting children at the species level

Yogyakarta and Bali. The dominant bacteria in the intestines of children in Yogyakarta and Bali were $61 \%$ versus $60 \%$ and Firmicutes and Bacteroidetes were $31 \%$ versus $30 \%$, while in Pasaman and West Pasaman district, West Sumatera Province, Indonesia, among stunting children, the dominant bacteria were Firmicutes, Proteobacteria, and Bacteroidetes. The high number of these microbiota associated with high amount of carbohydrate intake among stunting children than dietary protein.

\section{Discussion}

The results of the study found in the intestines of stunting children identified 61 species of bacteria which were only found in the intestines of stunting children and not found in non-stunting children. The intestinal microbiota profile of Pasaman and West Pasaman district, West Sumatera Province, Indonesia, showed the difference with children from Yogyakarta and Bali. The dominant bacteria in the intestines of children in Yogyakarta and Bali were $61 \%$ versus $60 \%$ and Firmicutes and Bacteroidetes were $31 \%$ versus $30 \%$, while in Pasaman and West Pasaman district, West Sumatera Province, Indonesia, among stunting children, 


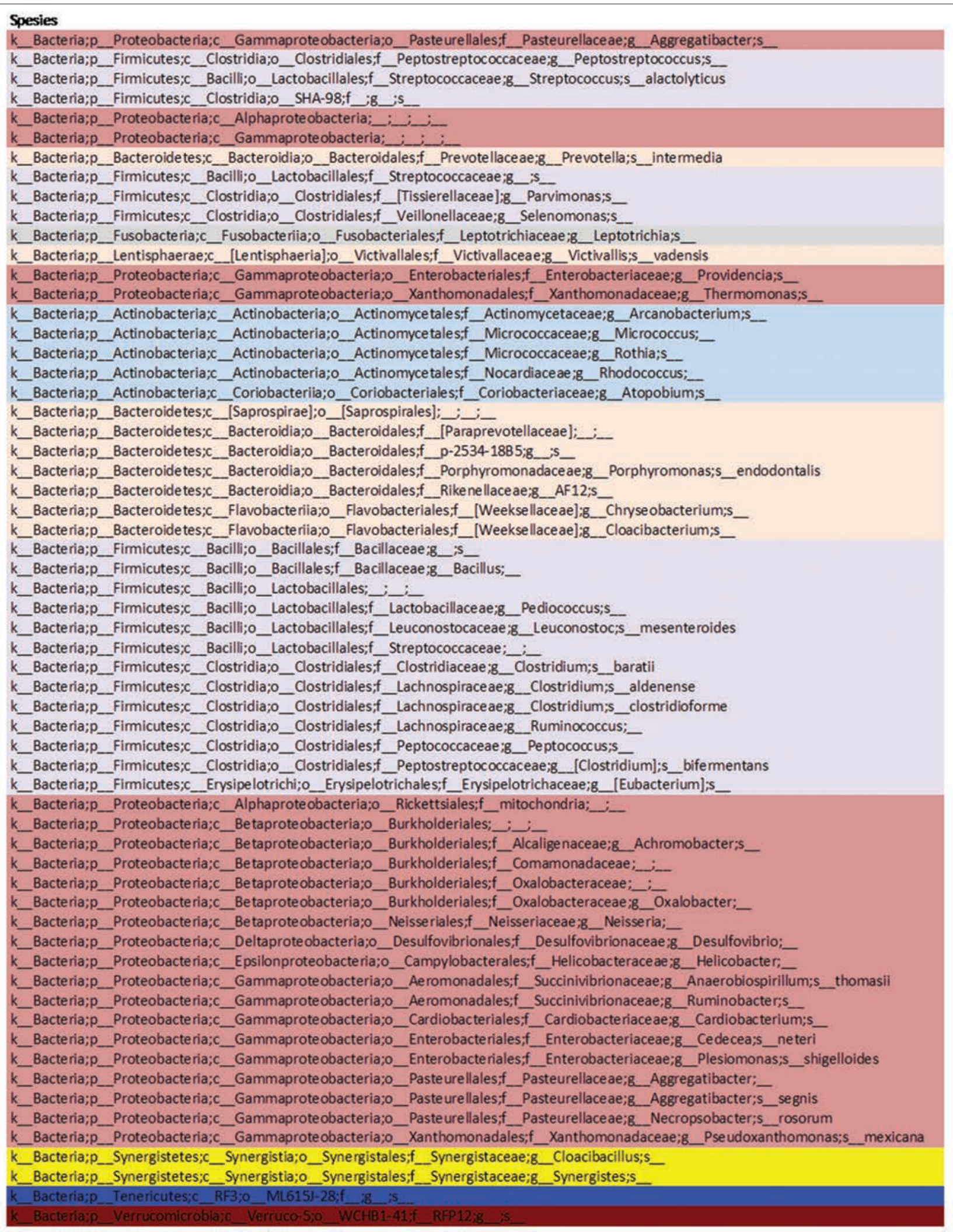

Figure 6: Pathogenic bacteria found in intestinal of stunting children

the dominant bacteria were Firmicutes, Proteobacteria, and Bacteroidetes. The high number of these microbiota associated with high amount of carbohydrate intake among stunting children than dietary protein.

The previous study showed that each individual has a different composition of the gastrointestinal microbiota. The age factor and area of residence can also determine the composition of this gastrointestinal microbiota. Stunting children in Bangladesh have different types and numbers of microbiota than children in the United States. However, children in the United States have a microbiota composition that is 


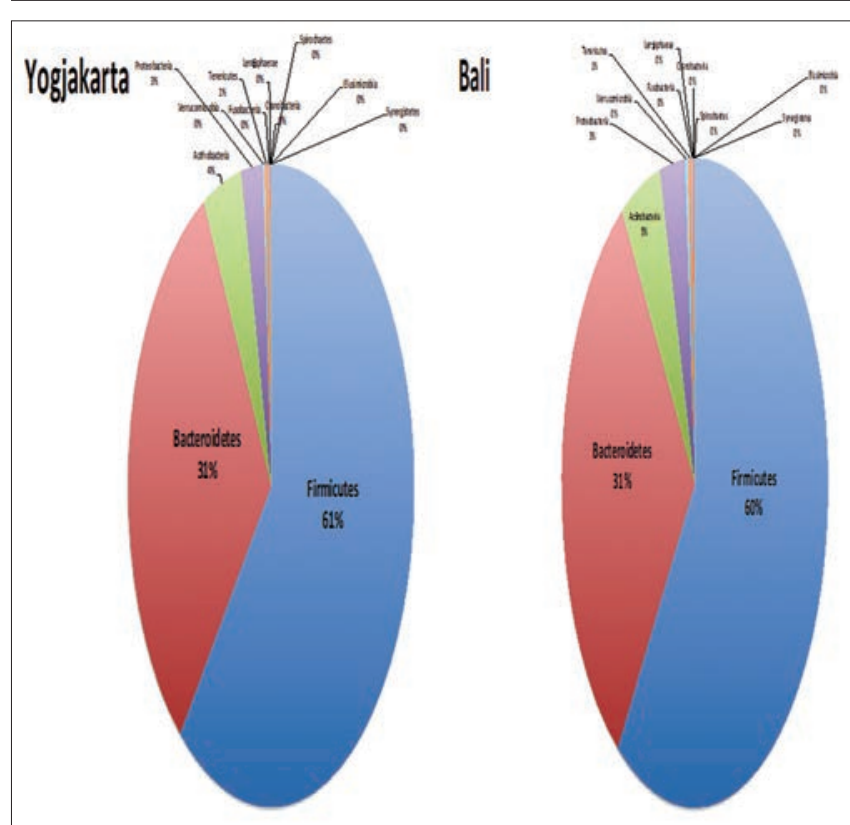

Figure 7: Comparison of types of the intestinal microbiota of stunting and normal children in Yogyakarta and Bali, Indonesia

relatively similar to adults in Bangladesh [8]. Microbiota populations can be affected by genetics and can change due to lifestyle, infectious diseases, antibiotic use, food intake, and other factors. Factors that affect children's nutritional status include a lack of nutrition and infectious diseases [9]. Poor nutritional intake of stunting children can be due to not fulfilling the amount or type of food needed and also the length of infection. This situation can cause changes in the composition of the digestive tract microbiota between pathogenic and commensal bacteria [10].

Previous study known gut microbiota of Indonesia children of varying nutritional status [11]. The worse the nutritional status of a child, the composition of microbiota in the digestive tract more pathogenic microbiota [11]. Other studies have also shown that stunting children, their digestive tract microbiota are rich in inflammogenic bacteria such as the genus Desulfovibrio and the order Campylobacterales [12].

Bacterial overgrowth in the small intestine is related to poor sanitation and stunting [13], [14]. This relationship can be explained by the mechanism of diarrhea. Excessive growth of pathogenic bacteria in the digestive tract caused by infection and low immunity will cause probiotics in the digestive tract to decrease. The composition of many pathogenic bacteria causes inflammation and malabsorption of nutrients causing stunting [14]. Infectious diseases and poor nutrition can cause environmental enteric dysfunction. This situation causes inflammation of the gastrointestinal tract, imbalance of the microbiota population in the gastrointestinal tract, and nutrient malabsorption. These conditions will cause linear growth to be disrupted [12], [14].
Based on this research, it is important in the preparation of stunting prevention interventions to pay attention to the intestinal microbiota dysfunction and systemic inflammation. This can help the accuracy of the intervention and its usefulness in overcoming stunting.

\section{Conclusion}

This study confirmed the role of microbiota profile in the incidence of stunting children.

\section{Acknowledgments}

We would like to thank the Ministry of Health, Republic of Indonesia for funding this research project and special thanks to all respondents who participated in this study.

\section{References}

1. Black RE, Victora CG, Walker SP. Maternal and child undernutrition and overweight in low-income and middleincome countries. Lancet. 2013;382(9890):427-51. https://doi. org/10.1016/s0140-6736(13)60937-x

PMid:23746772

2. Semba RD. Nutrition and development: A historical perspective. In: Semba RD, Bloem MW, editors. Nutrition and Health in Developing Countries. 2nd ed. Totowa, NJ: Humana Press: 2008. p. 1-31. https://doi.org/10.1007/978-1-59745-464-3_1

3. Ministry of Health Republic of Indonesia. Indonesia Basic Health Survey. Jakarta: Ministry of Health Republic of Indonesia; 2013. https://doi.org/10.25133/jpssv27n1.003

4. de Onis $M$, Onyango A, Borghi E. Worldwide implementation of the WHO child growth standards. Public Health Nutr. 2012;15(9):160310. https://doi.org/10.1017/s136898001200105x PMid:22717390

5. Murray CJ. Shifting to sustainable development goals-implications forglobal health. NEngl J Med. 2015;373(15):1390-3.

6. Bhutta ZA, Das JK, Rizvi A, Gaffey MF, Walker N, Horton S, Webb $\mathrm{P}$, et al. Evidence-based interventions for improvement of maternal and child nutrition: What can be done and at what cost? Lancet. 2013;382(9890):452-77. https://doi.org/10.1016/ s0140-6736(13)60996-4 PMid:23746776

7. Pham TP, Alou MT, Bachar D, Levasseur A, Brah S, Alhousseini $\mathrm{D}$, et al. Gut microbiota alteration is characterized by a proteobacteria and fusobacteria bloom in kwashiorkor and a bacteroidetes paucity in marasmus. Sci Rep. 2019;9(1):9084. https://doi.org/10.1038/s41598-019-45611-3

8. Lin A, Bik EM, Costello EK, Dethlefsen L, Haque R, Relman DA et al. Distinct distal gut microbiome diversity and composition 
in healthy children from Bangladesh and the United States. Plos One. 2013;8(1):e53838. https://doi.org/10.1371/journal. pone.0053838

PMid:23349750

9. Mwaniki EW, Makokha AN. Nutrition status and associated factors among children in public primary schools in Dagoretti, Nairobi, Kenya. Afr Health Sci. 2013;13(1):39-46. https://doi. org/10.4314/ahs.v13i1.6

PMid:23658566

10. Owino V, Ahmed T, Freemark M, Kelly P. Environmental enteric dysfunction and growth failure/stunting in global child health. Pediatrics. 2016;138(6):e20160641. https://doi.org/10.1542/ peds.2016-0641

PMid:27940670

11. Ghosh TS, Gupta SS, Bhattacharya T, Yadav D, Barik A, Chowdhury A, et al. Gut microbiomes of Indian children of varying nutritional status. Plos One. 2014;9(4):e95547. https:// doi.org/10.1371/journal.pone.0095547
PMid:24763225

12. Dinh DM, Ramadass $B$, Kattula $D$, Sarkar $R$, Braunstein $P$, Tai A, et al. Longitudinal analysis of the intestinal microbiota in persistently stunted young children in South India. Plos One. 2016;11(5):e0155405. https://doi.org/10.1371/journal. pone.0155405

PMid:27228122

13. Gough EK, Stephens DA, Moodie EE, Prendergast AJ, Stoltzfus RJ, Humphrey $\mathrm{JH}$, et al. Linear growth faltering in infants is associated with Acidaminococcus sp and communitylevel changes in the gut microbiota. Microbiome. 2015;3:24 https://doi.org/10.1186/s40168-015-0089-2.

PMid:26106478

14. Donowitz JR, Haque R, Kirkpatrick BD, Alam M, Lu M, Kabir M et al. Small intestine bacterial overgrowth and environmental enteropathy in Bangladeshi children. MBio. 2016;7(1):e0210215. https://doi.org/10.1128/mbio.02102-15

PMid:26758185 